\title{
Orexin-A controls sympathetic activity and eating behavior
}

\section{Giovanni Messina ${ }^{1}$, Carmine Dalia ${ }^{1}$, Domenico Tafuri ${ }^{2}$, Vincenzo Monda ${ }^{1}$, Filomena Palmieri ${ }^{1}$, Amelia Dato ${ }^{1}$, Angelo Russo ${ }^{1}$, Saverio De Blasio ${ }^{1}$, Antonietta Messina ${ }^{1}$, Vincenzo De Luca ${ }^{3}$, Sergio Chieffi ${ }^{1}$ and Marcellino Monda ${ }^{1}{ }^{*}$}

${ }^{1}$ Section of Human Physiology and Clinical Dietetic Service, Department of Experimental Medicine, Second University of Naples, Naples, Italy

2 Faculty of Motor Sciences, Parthenope University of Naples, Naples, Italy

${ }^{3}$ Department of Psychiatry, University of Toronto, Toronto, ON, Canada

\section{Edited by:}

Tanya Zilberter, Infotonic Conseil, France

\section{Reviewed by:}

Sylvia Richter, Paris-Lodron

Universität Salzburg, Austria

Willian Seiji Korim, The University of

Melbourne, Australia

${ }^{*}$ Correspondence:

Marcellino Monda, Section of Human Physiology and Clinical Dietetic

Service, Department of Experimental Medicine, Second University of

Naples, Via Costantinopoli 16,

Naples 80138, Italy

e-mail:marcellino.monda@unina2.it
It is extremely important for the health to understand the regulatory mechanisms of energy expenditure. These regulatory mechanisms play a central role in the pathogenesis of body weight alteration. The hypothalamus integrates nutritional information derived from all peripheral organs. This region of the brain controls hormonal secretions and neural pathways of the brainstem. Orexin-A is a hypothalamic neuropeptide involved in the regulation of feeding behavior, sleep-wakefulness rhythm, and neuroendocrine homeostasis. This neuropeptide is involved in the control of the sympathetic activation, blood pressure, metabolic status, and blood glucose level. This minireview focuses on relationship between the sympathetic nervous system and orexin-A in the control of eating behavior and energy expenditure. The "thermoregulatory hypothesis" of food intake is analyzed, underlining the role played by orexin-A in the control of food intake related to body temperature. Furthermore, the paradoxical eating behavior induced orexin-A is illustrated in this minireview.

Keywords: body weight, orexin-A, energy expenditure, sympathetic nervous system, behavior

\section{INTRODUCTION}

Obesity and diabetes are a worldwide public health issue with extensive medical, social, and economic consequences (Yach et al., 2006; Runge, 2007). Obesity (body mass index $\geq 30 \mathrm{~kg}$ of body weight $/ \mathrm{m}^{2}$ of height) has negative effects on health and increases the risk of developing a variety of diseases, including cardiovascular syndromes, some cancers, and diabetes mellitus (Must et al., 1999; Field et al., 2001; Calle et al., 2003; Friedenberg et al., 2008). Over the past three decades, the prevalence of obesity has doubled in the USA and in Europe (Ogden et al., 2006; Van Vliet-Ostaptchouk et al., 2014). Although according to the most recent data published in the 2005-2006 update of the National Health and Nutrition Examination Survey (NHANES) obesity rates have stabilized, others (Wang and Beydoun, 2007) expect that the obesity "epidemic" will only continue to worsen, with as many as $75 \%$ of Americans and of Europeans potentially being overweight in the year 2020. Physicians will undoubtedly encounter obese people in clinical practice and must, then, be able to identify and address care needs specific to this patient population.

This minireview focuses on relationship between the autonomic nervous system and orexin-A in the control of eating behavior, energy expenditure, and body weight regulation. The "thermoregulatory hypothesis" of food intake (Himms-Hagen, 1995) is analyzed, underlining the role played by orexin-A in the control of eating behavior related to body temperature.

\section{ENERGY HOMEOSTASIS}

Energy homeostasis is determined by the balance between intake of calories and energy expenditure. This is regulated by interconnected neuroendocrine and autonomic pathways (Monda et al., 2008a).

Resting energy expenditure (REE) accounts for $60-75 \%$ of total daily energy expenditure. Several factors contribute to the inter-individual variability in REE such as fat-free mass (FFM; Weyer etal., 1999), sympathetic nervous system (SNS) activity (Welle etal., 1991; Messina etal., 2012), and endocrine status [e.g., thyroid hormone (Danforth and Burger, 1984)]. REE decreases with age (Roubenoff et al., 2000). This decline is due not only to the loss of FFM and an alteration in its metabolically active components, but also to the reduction in physical activity.

\section{HYPOTHALAMUS AND OREXINS}

The hypothalamus, a key component for regulation of energy homeostasis, continuously monitors signals that reflect energy status and initiates appropriate behavioral and metabolic responses (Suzuki et al., 2012). It controls glucose utilization in insulinsensitive organs, such as skeletal muscle, as well as whole-body energy metabolism (Sudo et al., 1991; Haque et al., 1999).

Orexins A and B are hypothalamic neuropeptides, involved in the regulation of feeding behavior, sleep-wakefulness rhythm, and neuroendocrine homeostasis (Kukkonen et al., 2002; Monda et al., 2005; Viggiano et al., 2006), as reported in Figure 1.

These peptides derive from the prepro-orexin (preprohypocretin) gene, which encodes a precursor (130 amino acids in rodents, 131 residues in humans) that is cleaved into orexin-A (synonymous with hypocretin-1; 33 amino acids) and orexin-B (hypocretin-2; 28 residues; Sakurai et al., 1998). Orexins promote both arousal and feeding (Sweet et al., 1999). Orexin-A binds 


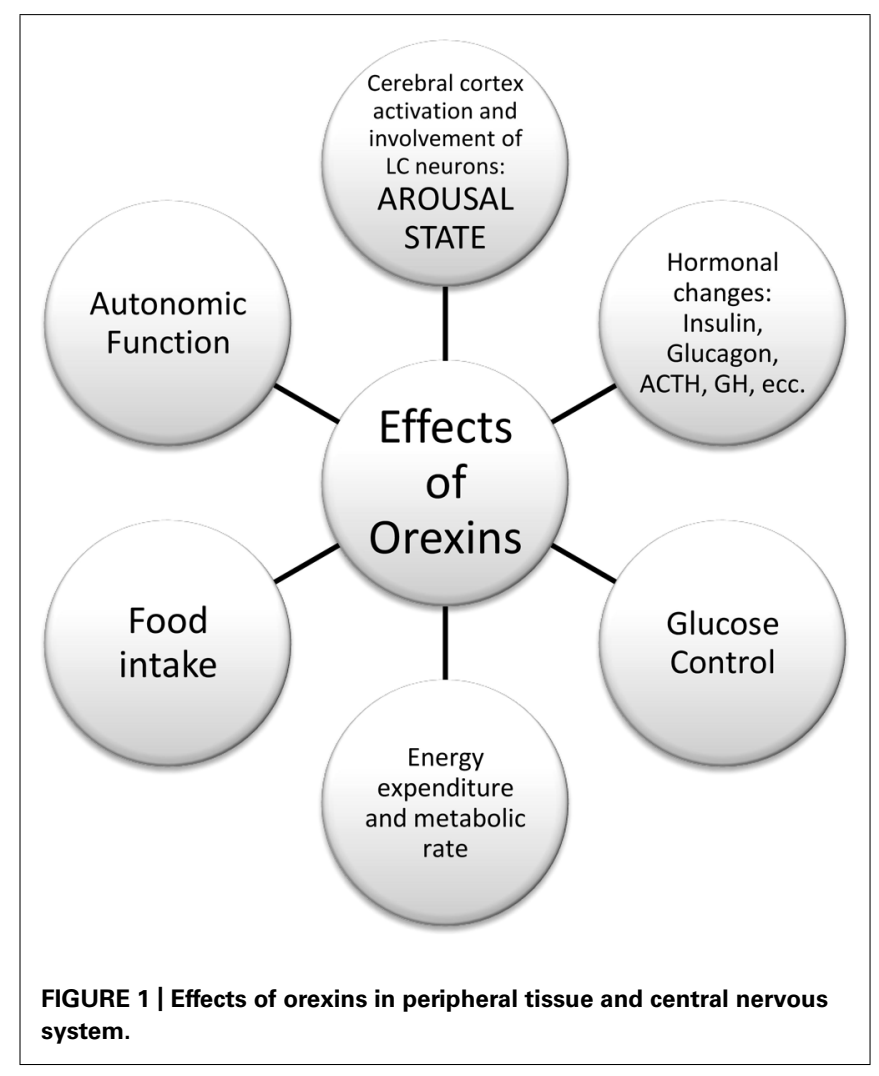

to two G-protein-coupled receptors, orexin receptor-1 (hypocretin receptor-1) and orexin receptor-2 (hypocretin receptor-2). The expression pattern of mRNA encoding two orexin receptors (OX1R andOX2R) in the rat's brain has been demonstrated (Trivedi et al., 1998; Machaalani et al., 2013). Within the hypothalamus, expression for the OX1R mRNA was largely restricted in the ventromedial (VMH) and dorsomedial hypothalamic nuclei, while paraventricular nucleus, $\mathrm{VMH}$, and arcuate nucleus contain high levels of OX2R mRNA, as well as in mammillary nuclei (Zhang etal., 2005). Lu etal. (2000) have demonstrated that levels of OX1R mRNA significantly increased in the $\mathrm{VMH}$ of rats after $20 \mathrm{~h}$ of fasting. An initial decrease $(14 \mathrm{~h})$ and a subsequent increase $(20 \mathrm{~h})$ in OX1R mRNA levels after fasting were observed in the dorsomedial hypothalamic nucleus. Levels of OX2R mRNA increased in the arcuate nucleus, but they didn't change in the dorsomedial hypothalamic nucleus and paraventricular hypothalamic nucleus following fasting (Lu et al., 2000).

Orexin neurons may also functionally interact with glucosesensitive neurons in the hypothalamus, notably the glucoseresponsive cells (glucose-excited neurons: stimulated by rising glucose levels) found predominantly in the $\mathrm{VMH}$, and the glucosesensitive neurons (glucose-inhibited neurons: stimulated when glucose falls) that constitute $30 \%$ of lateral hypothalamic area (LHA) neurons. There are synaptic contacts between orexin neurons and glucose-sensitive cells in the LHA (Shiraishi et al., 2000), while orexin-A specifically stimulates the glucose-sensitive cells (Liu etal., 2001). On the contrary, orexin-A inhibits glucoseresponsive neurons in the $\mathrm{VMH}$ (Shiraishi et al., 2000). Muroya et al. (2001) suggest that some glucose-sensitive neurons express orexins. In the medulla, orexin neurons innervate not only the ventral area (Zheng etal., 2005), but also the nucleus of the solitary tract (Ciriello etal., 2003), which is an important relay station that receives sensory signals, such as portal vein glucose availability and gastric distension from the viscera. These signals are conveyed to the hypothalamus (Horst et al., 1989).

Sugar-sensing neurons exist in restricted brain regions, such as hypothalamus and brain stem, and they are classified into two groups, called glucose-excited (GE) neurons and glucoseinhibited (GI) neurons, in terms of the mode of response to extracellular glucose changes within physiological cerebrospinal fluid (CSF) range (Burdakov and González, 2009; Gonzàlez et al., 2009). For instance, orexin neurons in the LHA and neuropeptide Y (NPY)/agouti-related peptide (AgRP) neurons in the ARC are glucose-inhibited, whereas melanin-concentrating hormone $(\mathrm{MCH})$ neurons in LHA and proopiomelanocortin (POMC) neurons in the ARC are glucose-excited (Burdakov et al., 2005; Burdakov and González, 2009). The sugar sensing of orexin neurons, which is a major class of GI neurons, is metabolism-independent, since the glucose response is unaffected by glucokinase inhibitors, and mimicked by a nonmetabolizable glucose analog 2-deoxyglucose (González et al., 2008), although the accurate mechanisms, particularly the functional molecules relevant to glucose-induced inhibition, have not yet been explained. Orexin neurons are not inhibited by Lglucose, galactose, $\alpha$-methyl-D-glucoside, or fructose, whereas GE neurons can sense galactose. More recently, it has been suggested that orexin neurons function as a "conditional glucosensor," because the electrical activity of orexin neurons is more potently inhibited by glucose when intracellular energy levels (i.e., cytosolic levels of pyruvate, lactate, or ATP) are low, whereas high energy levels attenuate the glucose response in orexin neurons (Venner et al., 2011). Besides, Yi et al. (2009) have reported that a continuous intracerebroventricula (ICV) infusion of orexin-A $(1 \mathrm{mmol} / \mathrm{L}, 5 \mu \mathrm{L} / \mathrm{h})$ into rats fasted for $5 \mathrm{~h}$ brought about an increase in plasma glucose levels, and prevented a daytime decrease of endogenous hepatic glucose production (EGP). Hepatic sympathetic, but not parasympathetic, denervation blocked the orexin induced apparent enhancement of EGP.

In addition, when the $\gamma$-aminobutyric acid receptor antagonist bicuculline was administered in the perifornical area in order to activate orexin neurons, basal EGP was increased, and insulinmediated suppression of EGP was attenuated, but the insulininduced glucose disposal was enhanced (Yi et al., 2009).

In addition, the presence of orexin receptors in other cerebral areas suggests that orexin-A plays additional functions (Kukkonen etal., 2002). It has been demonstrated that the orexins play a role in sleep regulation (Beuckmann and Yanagisawa, 2002). Deficiency in orexin neurotransmission results in the sleep disorder narcolepsy in mice, dogs, and humans (Monda et al., 2004a). Orexin derangements in patients with narcolepsy were associated with an increased body mass index (Schuld et al., 2000) and a higher risk of type-II diabetes mellitus (Honda et al., 1996). 
Orexins exert peripheral effect and this was suggested by the detection of substantial levels of orexins in plasma (Adam et al., 2002), as well as the presence of orexin receptors in several peripheral tissues, including the gastrointestinal tract (GIT), endocrine pancreas, adrenal glands, and adipose tissue (Digby et al., 2006; Heinonen et al., 2008).

Snow et al. (2002) have demonstrated that plasma orexin levels are one-fifth to one-eighth of orexin CSF values. However, the source of orexin in peripheral tissue is still unclear. Is orexin directly released into the blood stream or leaked from the CSF? One possibility is that orexin is released from the brain. The other possibility is that orexin is produced directly in peripheral tissues. Orexin-immunoreactive cells are observed in the gastrointestinal tract and pancreas. However, the question of orexin synthesis in peripheral tissue is still under discussion. Further studies are needed to better understand orexin physiology in peripheral tissues.

The influence of orexin-A on metabolic status and plasma glucose level may contribute to increase diabetics morbidity and mortality (Minokoshi et al., 1999). It has been proved that orexins affect the plasma lipoprotein profile and insulin glucose homeostasis (Muroya et al., 2001). Orexins stimulate insulin release from pancreatic cells in vivo and in vitro (Nowak et al., 2000). Several studies have focused on finding out the relationship between circulating orexin and fat mass and have proved that there is a strong correlation between low plasma orexin and obesity (Adam et al., 2002; Messina et al., 2013a). A significant issue is whether this naturally occurring biological peptide "orexin" in useful in weight management or obesity treatment. Many suggest that when orexin is peripherally injected, it activates thermogenesis, without limiting feeding or increasing physical activity. These encouraging observations have paved the way for clinical testing of the thermogenic potential of orexin (Messina et al., 2013b).

Orexin-A controls glucose production and utilization in the peripheral tissues via the autonomic nervous system (Tsuneki et al., 2010). These conclusions demonstrate that orexin is involved in the control of central and peripheral hormonal actions for the maintenance of glucose homeostasis, though it has been demonstrated that glucose control remains following decerebration (DiRocco and Grill, 1979). Existing evidence suggests that orexins induce glucose production in the liver (Stanley et al., 2010) and help glucose uptake in skeletal muscle (Yi et al., 2009). In addition it has been shown that orexins A and B differentially regulate glucagon release from pancreas (Bass and Takahashi, 2010).

In summary, there is substantial evidence in the literature that helps to define the physiological role of orexin neurons, and their connections, as reported in Figure 2. For instance, anatomical works by Kilduff and Peyron (2000) and Kerman (2008); physiological studies by Karnani and Burdakov (2011) and Inutsuka and Yamanaka (2013) in glucose-regulation, and Morrison et al. (2012a) in thermoregulation. More recently, opto- and pharmacogenetic tools also have been used to investigate the physiological role of these neurons (Heydendael et al., 2014; Inutsuka et al., 2014). Finally, hypothalamic orexin neurons co-express glutamate vesicular transporters (Rosin et al., 2003), suggesting an important role of this neurotransmitter in the orexinergic pathway.

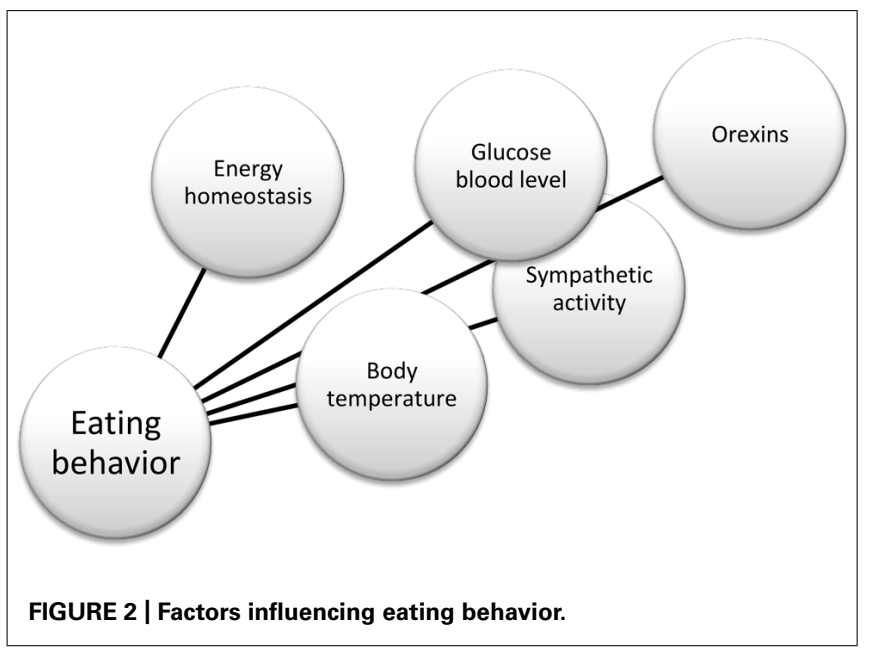

\section{THE SYMPATHETIC NERVOUS SYSTEM}

Eating is a complex behavior that partly involves the sympathetic nervous system. This sympathetic involvement is exerted by an influence on body temperature, in agreement with the "thermoregulatory hypothesis" of eating behavior (Himms-Hagen, 1995). Obviously, the role of the sympathetic system in controlling the eating behavior is not restricted only to changes in body temperature. For instance, the aforementioned glucose-control involves the sympathetic system.

Orexin-A also influences body temperature. In fact, an ICV administration of orexin-A induces an increase in firing rate of the sympathetic nerves to BAT, accompanied with a rise in BAT and colonic temperatures (Monda et al., 2001). The simultaneous increase in heart rate and body temperature after an ICV injection of orexin-A shows a generalized activation of the sympathetic nervous system. Few studies have been made on the topic of the roles played by different cerebral areas involved in the induction of the above-mentioned tachycardia and hyperthermia (Monda et al., 1994, 1995, 1996).

The sympathetic adjustment of thermoregulation also implies in energy expenditure. The functional organization and neurochemical influences within the CNS networks governs the level of BAT sympathetic nerve activity to produce the thermoregulatory and metabolically driven alterations in BAT thermogenesis and energy expenditure that contribute to overall energy homeostasis (Morrison et al., 2014). BAT thermogenesis contributes to the maintenance of body temperature during cold exposure and to the elevated core temperature during several behavioral states, including wakefulness, the acute phase response (fever), and stress. BAT energy expenditure requires metabolic fuel availability and contributes to energy balance.

The consequences of the "thermoregulatory hypothesis" of eating behavior are that subjects with a high set-point of body temperature and/or low sympathetic activity are induced to eat a high quantity of food to elevate the sympathetic discharge and body temperature. Many studies (Keesey and Hirvonen, 1997; Morrison et al., 2012b) indicate that some forms of obesity can be regarded as instances of regulation at an elevated set point, 
while other forms seemingly result from a regulatory dysfunction, as already reported by Keesey (1988).

Conversely, subjects with a low thermal set-point and/or a high sympathetic tone need to introduce a lower quantity of food to reach a prefixed thermal set-point. Alterations of postprandial thermogenesis due to a reduced response of sympathetic activation can play an important role in inducing obesity. In other words, subjects with a low postprandial sympathetic activation need to introduce a higher quantity of foot to reach a prefixed body temperature. On the other hand, being overweight increases the sympathetic discharge that contributes to induce diseases related to abnormal body weight (Lambert et al., 2010).

Chronic sympathetic over activity is also known to be present in central obesity, and many evidences demonstrate the consequence of a high sympathetic outflow to organs such as the heart, kidneys, and blood vessels. Chronic sympathetic nervous system over activity can also contribute to a further decline of insulin sensitivity, creating a vicious cycle that may lead to the development of the metabolic syndrome and hypertension. The cause of this over activity is not clear, but may be driven by certain adipokines (Smith and Minson, 2012). In addition, the postprandial activation of the peripheral sympathetic nervous system is fundamental to maintain energy balance. A contribution of postprandial sympathetic activation to the thermic effect of food is not always evident and depends on the size and composition of the meal, with carbohydrates having the clearest effect. Signals related to food intake from various origins (e.g., gut, hepatoportal area, chemoreceptors) are integrated in the brain and result in increased peripheral sympathetic outflow. It is of interest to emphasize the role of diet composition (according to the life style of subjects) in the level of sympathetic activation during the day in view of the potential role of adrenergic over activity in the pathogenesis of obesity and its metabolic syndrome (Van Baak, 2008).

Power spectral analysis (PSA) of the heart rate variability (HRV) is considered a non-invasive method for quantitative and qualitative evaluation of the autonomic nervous system activity in various fields of research and clinical studies. In the frequency domain method of HRV, the high frequency (HF) component is associated solely with parasympathetic activity. The low frequency (LF) component is associated with both sympathetic and parasympathetic activities, but sympathetic activity is the greater contributor. LF power may correlate more with baroreflex function and/or stress that with the cardiac sympathetic innervations (Moak et al., 2007; Shah et al., 2011).

This approach should modify the interpretations about the sympathetic function in the pathophysiology of the obesity. In a study conducted in our laboratory (Monda et al., 2006a), we demonstrated that LF and HF values of premenopausal obese women were lower than values of lean women. In postmenopause, LF and HF have a comparable decline in lean and obese women, as a consequence no difference can be found. These results suggest a reduction of the vegetative modulation in obese young women and the reduction of the autonomic control regards both the sympathetic and parasympathetic components (Monda et al., 2006b). The reduction of the sympathetic branch could be an important factor in the maintenance of obesity in premenopausal age.
Indeed, a reduction in the sympathetic activity could be linked to a low energy expenditure, so that a reduced energetic cost could explain the higher body weight in premenopausal women. In this experiment, the autonomic activity of postmenopausal women is lower than that of premenopausal subjects, though a better indicator of the sympathetic activity would be very low frequencies (Fleisher et al., 1996). This indicates that the modifications of the autonomic modulation cannot be included among factors related to obesity in postmenopausal subjects. Many experimental evidences have demonstrated that an increase in sympathetic and thermogenic activity reduces food intake. Therefore, the obesity can be due to an increase in food intake associated to a reduced activity of the sympathetic nervous system. On the other hand, a study revealed lower respiratory sinus arrhythmia, as evaluated by the HF-HRV spectral analysis combined with deep breathing tests, which points to the presence of cardiac vagal dysfunction in obese adolescents (Tonhajzerova et al., 2008). Importantly, autonomic imbalance with decreased parasympathetic activity maybe the final common pathway in numerous conditions associated with increased morbidity and mortality (Thayer and Lane, 2007). The evaluation of cardio respiratory interactions, in particular the heart rate variability, can provide diagnostic information about early subclinical autonomic dysfunction in obesity. Traditionally, there have been two hypotheses about the nature of the predominate abnormality in SNS behavior in human obesity. Bray (1991) used the acronym "MONA LISA" to describe his hypothesis that Most Obesities kNown Are Low In Sympathetic Activity. This vision was based principally on studies in rodents that exhibited low SNS activity and morbid obesity following lesions in the ventromedial hypothalamus. As such, low SNS activity was considered causal in the development of obesity. In contrast, Landsberg (1986) viewed SNS activation targeting the heart, blood vessels and kidneys as a critical relation to the well documented relation between obesity and hypertension (Hall, 2003; Davy and Hall, 2004).

\section{PARADOXICAL EATING BEHAVIOR: HYPERPHAGIA AND HYPOPHAGIA BY OREXIN-A}

Since orexin-A is able to induce both the activation of thermogenesis and hyperphagia, Monda et al. (2003) tested the possibility that a previous thermogenic activation induced by orexin-A can modify eating behavior. Food intake and body temperature were monitored in $24 \mathrm{~h}$-fasting male Sprague-Dawley rats for $15 \mathrm{~h}$ after food presentation during the dark period. Orexin-A was injected into the lateral cerebral ventricle $6 \mathrm{~h}$ before food presentation. Food intake and body temperature were controlled also in rats receiving orexin- $\mathrm{A}$ at the same time of food presentation. Orexin-A caused the same elevation of body temperature in both groups, while food intake was significantly lower in the group receiving orexin-A $6 \mathrm{~h}$ before food presentation in comparison to the other group. This study demonstrated that the effects on food intake induced by orexin-A depend on the time of food presentation. This suggest to revise the role of orexin-A in the control of food intake. The name assigned to this peptide was due to the strong increase in food intake after an orexin-A administration, assigning a fundamental role in the induction of food intake (Wolf, 1998; Shiraishi et al., 2000). The results 
of the above publication call for a re-discussion of this role, underlining the importance of orexin-A in the control of the sympathetic activity and body temperature, which in turn affects food intake. An ICV injection of orexin-A induces an increase in the sympathetic activity and in the body temperature independently of food ingestion, that is reduced in the rats with a delayed presentation of food. This suggests that the effects on body temperature are prevalent with respect to eating behavior. Then, orexin-A can induce hyperphagia, but also hypophagia, contradicting the significance of this name that assign a primary hyperphagic effect to this peptide. For this reason, orexin-A cannot be considered a substance with a primary hyperphagic effect.

Orexin-A can induce hypophagia or hyperphagia (Shiraishi et al., 2000), but it always induces an activation of thermogenesis (Monda et al., 2004b, 2008b). We believe that this peptide elevates the thermoregulatory set-point, inducing the reactions to reach the new level of body temperature. The increase in food intake, obtained in the rats with a non-delayed presentation of food, could be a reaction aimed to reach an elevated body temperature. Indeed, food ingestion induces a rise in body temperature due to postprandial thermogenesis (De Luca etal., 1987; Tentolouris etal., 2006; Monda etal., 2008a; Messina etal., 2012, 2013a). The hyperphagic effect of orexin-A disappears when the body temperature is already increased, so that a reduction in food intake can happen in this condition.

Although selective activation of orexin neurons directly can elicit eating behavior (Inutsuka et al., 2014), the above-reported demonstrations support the idea that orexin-A controls body temperature and subsequently eating behavior.

\section{REFERENCES}

Adam, J. A., Menheere, P. P. C. A., Van Dielen, F. M. H., Soeters, P. B., Buurman, W. A., and Greve, G. W. (2002). Decreased plasma orexin-A levels in obese individuals. Int. J. Obes. 26, 274-266. doi: 10.1038/sj.ijo.0801868

Bass, J., and Takahashi, J. S. (2010). Circadian integration of metabolism and energetics. Science 330, 1349-1354. doi: 10.1126/science.1195027

Beuckmann, C. T., and Yanagisawa, M. (2002). Orexins: from neuropeptides to energy homeostasis and sleep/wake regulation. J. Mol. Med. 80, 329-342. doi: 10.1007/s00109-002-0322-x

Bray, G. A. (1991). Obesity, a disorder of nutrient partitioning: the MONA LISA hypothesis. J. Nutr. 121, 1146-1162.

Burdakov, D., and González, J. A. (2009). Physiological functions of glucoseinhibited neurones. Acta Physiol. (Oxf.) 195, 71-78. doi: 10.1111/j.17481716.2008.01922.x

Burdakov, D., Luckman, S. M., and Verkhratsky, A. (2005). Glucose-sensing neurons of the hypothalamus. Philos. Trans. R. Soc. Lond. B Biol. Sci. 360, 2227-2235. doi: 10.1098/rstb.2005.1763

Calle, E. E., Rodriguez, C., Walker-Thurmond, K., and Thun, M. J. (2003). Overweight, obesity, and mortality from cancer in a prospectively studied cohort of U.S. adults. N. Engl. J. Med. 348, 1625-1638. doi: 10.1056/NEJMoa021423

Ciriello, J., McMurray, J. C., Babic, T., and de Oliveira, C. V. (2003). Collateral axonal projections from hypothalamic hypocretin neurons to cardiovascular sites in nucleus ambiguus and nucleus tractus solitarius. Brain Res. 991, 133-141. doi: 10.1016/j.brainres.2003.08.016

Danforth, E. Jr., and Burger, A. (1984). The role of thyroid hormones in the control of energy expenditure. Clin. Endocrinol. Metab. 13, 581-595. doi: 10.1016/S0300595X(84)80039-0

Davy, K. P., and Hall, J. E. (2004). Obesity and hypertension: two epidemics or one? Am. J. Physiol. Regul. Integr. Comp. Physiol. 286, R803-R813. doi: 10.1152/ajpregu.00707.2003
De Luca, B., Monda, M., Pellicano, M. P., and Zenga, A. (1987). Cortical control of thermogenesis induced by lateral hypothalamic lesion and overeating. Am. J. Physiol. Regul. Integr. Comp. Physiol. 253, R626-R633.

Digby, J. E., Chen, J., Tang, J. Y., Lehnert, H., Matthews, R. N., and Randeva, H. S. (2006). Orexin receptor expression in human adipose tissue: effects of orexin-A and orexin-B. J. Endocrinol. 19, 129-136. doi: 10.1677/joe.1. 06886

DiRocco, R. J., and Grill, H. J. (1979). The forebrain is not essential for sympathoadrenal hyperglycemic response to glucoprivation. Science 204, 1112-1114. doi: $10.1126 /$ science. 451558

Field, A. E., Coakley, E. H., Must, A., Spadano, J. L., Laird, N., Dietz, W. H., et al. (2001). Impact of overweight on the risk of developing common chronic diseases during a 10-year period. Arch. Intern. Med. 161, 1581-1586. doi: 10.1001/archinte.161.13.1581

Fleisher, L. A., Frank, S. M., Sessler, D. I., Cheng, C., Matsukawa, T., and Vannier, C. A. (1996). Thermoregulation and heart rate variability. Clin. Sci. (Lond.) 90, 97-103.

Friedenberg, F. K., Xanthopoulos, M., Foster, G. D., and Richter, J. E. (2008). The association between gastroesophageal reflux disease and obesity. Am. J. Gastroenterol. 103, 2111-2122. doi: 10.1111/j.1572-0241.2008.01946.x

González, J. A., Jensen, L. T., Fugger, L., and Burdakov, D. (2008). Metabolismindependent sugar sensing in central orexin neurons. Diabetes 57, 2569-2576. doi: $10.2337 / \mathrm{db} 08-0548$

Gonzàlez, J. A., Reimann, F., and Burdakov, D. (2009). Dissociation between sensing and metabolism of glucose in sugar sensing neurones. J. Physiol. (Lond.) 587, 41-48. doi: 10.1113/jphysiol.2008.163410

Hall, J. E. (2003). The kidney, hypertension, and obesity. Hypertension 41, 625-633. doi: 10.1161/01.HYP.0000052314.95497.78

Haque, M. S., Minokoshi, Y., Hamai, M., Iwai, M., Horiuchi, M., and Shimazu, T. (1999). Role of the sympathetic nervous system and insulin in enhancing glucose uptake in peripheral tissues after intrahypothalamic injection of leptin in rats. Diabetes 48, 1706-1712. doi: 10.2337/diabetes.48.9.1706

Heinonen, M. V., Purhonen, A. K., Makela, A. K., and Herzig, K. H. (2008). Functions of orexins in peripheral tissues. Acta Physiol. 192, 471-485. doi: 10.1111/j.17481716.2008.01836.x

Heydendael, W., Sengupta, A., Beck, S., and Bhatnagar, S. (2014). Optogenetic examination identifies a context-specific role for orexins/hypocretins in anxietyrelated behavior. Physiol. Behav. 130, 182-190. doi: 10.1016/j.physbeh.2013. 10.005

Himms-Hagen, J. (1995). Role of brown adipose tissue thermogenesis in control of thermoregulatory feeding in rats: a new hypothesis that links thermostatic and glucostatic hypotheses for control of food intake. Proc. Soc. Exp. Biol. Med. 208, 159-169. doi: 10.3181/00379727-208-43847A

Honda, Y., Doi, Y., Ninomiya, R., and Ninomiya, C. (1996). Increased frequency of non-insulin-dependent diabetes mellitus among narcoleptic patients. Sleep 9 , 254-259.

Horst, G. J. T., de Boer, P., Luiten, P. G. M., and van Willigen, J. D. (1989). Ascending projections from the solitary tract nucleus to the hypothalamus: a phaseolus valgaris lectin tracing study in the rat. Neuroscience 31, 785-797. doi: 10.1016/0306-4522(89)90441-7

Inutsuka, A., Inui, A., Tabuchi, S., Tsunematsu, T., Lazarus, M., and Yamanaka, A. (2014). Concurrent and robust regulation of feeding behaviors and metabolism by orexin neurons. Neuropharmacology 85, 451-460. doi: 10.1016/j.neuropharm.2014.06.015

Inutsuka, A., and Yamanaka, A. (2013). The regulation of sleep and wakefulness by the hypothalamic neuropeptide orexin/hypocretin. Nagoya J. Med. Sci. 75, 29-36.

Karnani, M., and Burdakov, D. (2011). Multiple hypothalamic circuits sense and regulate glucose levels. Am. J. Physiol. 300, R47-R55. doi: 10.1152/ajpregu.00527.2010

Keesey, R. E. (1988). The body-weight set point. What can you tell your patients? Postgrad. Med. 83, 114-118.

Keesey, R. E., and Hirvonen, M. D. (1997). Body weight set-points: determination and adjustment. J. Nutr. 127, 1875S-1883S.

Kerman, I. A. (2008). Organization of brain somatomotor-sympathetic circuits. Exp. Brain Res. 187, 1-16. doi: 10.1007/s00221-008-1337-5

Kilduff, T. S., and Peyron, C. (2000). The hypocretin/orexin ligand-receptor system: implications for sleep and sleep disorders. Trends Neurosci. 23, 359-365. doi: 10.1016/S0166-2236(00)01594-0 
Kukkonen, J. P., Holmqvist, T., Ammoun, S., and Akerman, K. E. (2002). Functions of the orexinergic/hypocretinergic system. Am. J. Physiol. 283, 1567-1591. doi: 10.1152/ajpcell.00055.2002

Lambert, G. W., Straznicky, N. E., Lambert, E. A., Dixon, J. B., and Schlaich, M. P. (2010). Sympathetic nervous activation in obesity and the metabolic syndromecauses, consequences and therapeutic implications. Pharmacol. Ther. 126, 159172. doi: 10.1016/j.pharmthera.2010.02.002

Landsberg, L. (1986). Diet, obesity and hypertension: an hypothesis involving insulin, the sympathetic nervous system, and adaptive thermogenesis. Q. J. Med. 61, 1081-1090.

Liu, X. H., Morris, R., Spiller, D., White, M., and Williams, G. (2001). Orexin-A preferentially excites glucose-sensitive neurons in the lateral hypothalamus of rats in vitro. Diabetes 50, 2431-2437. doi: 10.2337/diabetes.50.11.2431

Lu, X. Y., Bagnol, D., Burke, S., Akil, H., and Watson, S. J. (2000). Differential distribution and regulation of OX1 and OX2 orexin/hypocretin receptor messenger RNA in the brain upon fasting. Horm. Behav. 37, 335-344. doi 10.1006/hbeh.2000.1584

Machaalani, R., Hunt, N. J., and Waters, K. A. (2013). Effects of changes in energy homeostasis and exposure of noxious insults on the expression of orexin(hypocretin) and its receptors in the brain. Brain Res. 1526, 102-122. doi: 10.1016/j.brainres.2013.06.035

Messina, G., De Luca, V., Viggiano, A., Ascione, A., Iannaccone, T., Chieffi, S., et al. (2013a). Autonomic nervous system in the control of energy balance and body weight: personal contributions. Neurol. Res. Intern. 3:639280. doi: $10.1155 / 2013 / 639280$

Messina, G., Viggiano, A., De Luca, V., Messina, A., Chieffi, S., and Monda, M. (2013b). Hormonal changes in menopause and orexin-a action. Obst. Gynec. Intern. 2013:209812. doi: 10.1155/2013/209812

Messina, G., Vicidomini, C., Viggiano, A., Tafuri, D., Cozza, V., Cibelli, G., et al. (2012). Enhanced parasympathetic activity of sportive women is paradoxically associated to enhanced resting energy expenditure. Auton. Neurosci. 169, 102-106. doi: 10.1016/j.autneu.2012.05.003

Minokoshi, Y., Haque, M. S., and Shimazu, T. (1999). Microinjection of leptin into the ventromedial hypothalamus increases glucose uptake in peripheral tissues in rats. Diabetes 48:287291. doi: 10.2337/diabetes.48.2.287

Moak, J. P., Goldstein, D. S., Eldadah, B. A., Saleem, A., Holmes, C., Pechnik, S., et al (2007). Supine low-frequency power of heart rate variability reflects baroreflex function, not cardiac sympathetic innervations. Heart Rhythm 4, 1523-1529. doi: 10.1016/j.hrthm.2007.07.019

Monda, M., Amaro, S., Sullo, A., and De Luca, B. (1994). Posterior hypothalamic activity and cortical control during the PGE1 hyperthermia. Neuroreport 6, 135139. doi: 10.1097/00001756-199412300-00035

Monda, M., Amaro, S., Sullo, A., and De Luca, B. (1995). Injection of muscimol in the posterior hypothalamus reduces the PGE1-hyperthermia in the rat. Brain Res. Bull. 37, 575-580. doi: 10.1016/0361-9230(95)00032-A

Monda, M., Messina, G., Vicidomini, C., Viggiano, A., Mangoni, C., and De Luca, B (2006a). Activity of autonomic nervous system is related to body weight in premenopausal, but not in post-menopausal women. Nutr. Neurosci. 9, 141-145. doi: 10.1080/10284150600903552

Monda, M., Viggiano, A., Viggiano, A., Viggiano, E., Messina, G., Tafuri, D., et al. (2006b). Quetiapine lowers sympathetic and hyperthermic reactions due to cerebral injection of orexin A. Neuropeptides 40, 357-363. doi: 10.1016/j.npep.2006.07.003

Monda, M., Messina, G., Mangoni, C., and De Luca, B. (2008a). Resting energy expenditure and fat-free mass do not decline during aging in severely obese women. Clin. Nutr. 27, 657-659. doi: 10.1016/j.clnu.2008.04.005

Monda, M., Viggiano, A., Viggiano, A., Mondola, R., Viggiano, E., Messina, G., etal. (2008b). Olanzapine blocks the sympathetic and hyperthermic reactions due to cerebral injection of orexin A. Peptides 29, 120-126. doi: 10.1016/j.peptides.2007.10.016

Monda, M., Sullo, A., De Luca, E., and Pellicano, M. P. (1996). Lysine acetylsalicylate modifies aphagia and thermogenic changes induced by lateral hypothalamic lesion. Am. J. Physiol. 271, R1638-R1642.

Monda, M., Viggiano, A., and De Luca, V. (2003). A paradoxical effect of orexin A: the hypophagia induced by hyperthermia. Brain Res. 961, 220-228. doi: 10.1016/S0006-8993(02)03953-7

Monda, M., Viggiano, A., Mondola, P., and De Luca, V. (2001). Inhibition of prostaglandin synthesis reduces hyperthermic reactions induced by hypocretin-1/orexin A. Brain Res. 909, 68-74. doi: 10.1016/S0006-8993(01) 02606-3

Monda, M., Viggiano, A., Viggiano, A., Fuccio, F., and De Luca, V. (2004a). Injection of orexin A into the diagonal band of Broca induces sympathetic and hyperthermic reactions. Brain Res. 1018, 265-271. doi: 10.1016/j.brainres.2004. 05.084

Monda, M., Viggiano, A., Viggiano, A., Fuccio, F., and De Luca, V. (2004b). Clozapine blocks sympathetic and thermogenic reactions induced by orexin A in rat. Physiol. Res. 53, 507-513.

Monda, M., Viggiano, A. N., Viggiano, A., Viggiano, E., Lanza, A., and De Luca, V. (2005). Hyperthermic reactions induced by orexin A: role of the ventromedial hypothalamus. Eur. J. Neurosci. 22, 1169-1175. doi: 10.1111/j.14609568.2005.04309.x

Morrison, S. F., Madden, C. J., and Tupone, D. (2012a). An orexinergic projection from perifornical hypothalamus to raphe pallidus increases rat brown adipose tissue thermogenesis. Adipocyte 1, 116-120. doi: 10.4161/adip.19736

Morrison, S. F., Madden, C. J., and Tupone, D. (2012b). Central control of brown adipose tissue thermogenesis. Front. Endocrinol. (Lausanne) 3:5. doi: 10.3389/fendo.2012.00005

Morrison, S. F., Madden, C. J., and Tupone, D. (2014). Central neural regulation of brown adipose tissue thermogenesis and energy expenditure. Cell Metab. 19, 741-756. doi: 10.1016/j.cmet.2014.02.007

Muroya, S., Uramura, K., Sakurai, T., Takigawa, M., and Yada, T. (2001). Lowering glucose concentrations increases cytosolic $\mathrm{Ca}^{2+}$ in orexin neurons of the rat lateral hypothalamus. Neurosci. Lett. 309, 165-168. doi: 10.1016/S03043940(01)02053-5

Must, A., Spadano, J., Coakley, E. H., Field, A. E., Colditz, G., and Dietz, W. H. (1999). The disease burden associated with overweight and obesity. JAMA 282, 1523-1529. doi: 10.1001/jama.282.16.1523

Nowak, K. W., Mac kowiak, P., Switonska, M. M., Fabis, M., and Malendowicz, L. K. (2000). Acute orexin effects on insulin secretion in the rat: in vivo and in vitro studies. Life Sci. 66, 449-454. doi: 10.1016/S0024-3205(99)00611-6

Ogden, C. L., Carroll, M. D., Curtin, L. R., McDowell, M. A., Tabak, C. J., and Flegal, K. M. (2006). Prevalence of overweight and obesity in the United States, 1999-2004. JAMA 295, 1549-1555. doi: 10.1001/jama.295.13.1549

Rosin, D. L., Weston, M. C., Sevigny, C. P., Stornetta, R. L., and Guyenet, P. G. (2003). Hypothalamic orexin (hypocretin) neurons express vesicular glutamate transporters VGLUT1 or VGLUT2. J. Comp. Neurol. 465, 593-603. doi: $10.1002 / \mathrm{cne} .10860$

Roubenoff, R., Hughes, V. A., Dallal, G. E., Nelson, M. E., Morganti, C., Kehayias, J. J., et al. (2000). The effect of gender and body composition method on the apparent decline in lean mass-adjusted resting metabolic rate with age. J. Gerontol. A Biol. Sci. Med. Sci. 55, M757-M760. doi: 10.1093/gerona/55.12.M757

Runge, C. F. (2007). Economic consequences of the obese. Diabetes 56, 2668-2672. doi: $10.2337 / \mathrm{db} 07-0633$

Sakurai, T., Amemiya, A., Ishii, M., Matsuzaki, I., Chemelli, R. M., Tanaka, H., et al. (1998). Orexins and orexin receptors: a family of hypothalamic neuropeptides and $\mathrm{G}$ protein-coupled receptors that regulate feeding behavior. Cell 92, 573-585. doi: 10.1016/S0092-8674(00)80949-6

Schuld, A., Hebebrand, J., Geller, F., and Pollmacher, T. (2000). Increased body-mass index in patients with narcolepsy. Lancet 355, 1274-1275. doi: 10.1016/S01406736(05)74704-8

Shah, A. J., Su, S., Veledar, E., Bremner, J. D., Goldstein, F. C., Lampert, R., et al. (2011). Is heart rate variability related to memory performance in middle-aged men? Psychosom. Med. 73, 475-482. doi: 10.1097/PSY.0b013e3182227d6a

Shiraishi, T., Oomura, Y., Sasaki, K., and Wayner, M. J. (2000). Effects of leptin and orexin-A on food intake and feeding related hypothalamic neurons. Physiol. Behav. 71, 251-261. doi: 10.1016/S0031-9384(00)00341-3

Smith, M. M., and Minson, C. T. (2012). Obesity and adipokines: effects on sympathetic overactivity. J. Physiol. 590, 1787-1801. doi: 10.1113/jphysiol.2011.221036

Snow, A., Gozal, E., Malhotra, A., Tiosano, D., Perlman, R., Vega, C., et al. (2002). Severe hypersomnolence after pituitary/hypothalamic surgery in adolescents: clinical characteristics and potential mechanisms. Pediatrics 110:e74. doi: 10.1542/peds.110.6.e74

Stanley, S., Pinto, S., Segal, J., Pérez, C. A., Viale, A., DeFalco, J., et al. (2010). Identification of neuronal subpopulations that project from hypothalamus to both liver and adipose tissue polysynaptically. Proc. Natl. Acad. Sci. U.S.A. 107, 7024-7029. doi: 10.1073/pnas.1002790107 
Sudo, M., Minokoshi, Y., and Shimazu, T. (1991). Ventromedial hypothalamic stimulation enhances peripheral glucose uptake in anesthetized rats. Am. J. Physiol. 261, E298-E303.

Suzuki, K., Jayasena, C. N., and Bloom, S. R. (2012). Obesity and appetite control. Exp. Diabetes Res. 2012:824305. doi: 10.1155/2012/824305.

Sweet, D. C., Levine, A. S., Billington, C. J., and Kotz, C. M. (1999). Feeding response to central orexins. Brain Res. 821, 535-538. doi: 10.1016/S0006-8993(99)01136-1

Tentolouris, N., Liatis, S., and Katsilambros, N. (2006). Sympathetic system activity in obesity and metabolic syndrome. Ann. N. Y. Acad. Sci. 1083, 129-152. doi: 10.1196/annals.1367.010

Thayer, J. F., and Lane, R. D. (2007). The role of vagal function in the risk for cardiovascular disease and mortality. Biol. Psychol. 74, 224-242. doi: 10.1016/j.biopsycho.2005.11.013

Tonhajzerova, I., Javorka, M., Trunkvalterova, Z., Chroma, O., Javorkova, J., Lazarova, Z., et al. (2008). Cardio-respiratory interaction and autonomic dysfunction in obesity. J. Physiol. Pharmacol. 59, 709-718. doi: 10.2106/JBJS.I.00705

Trivedi, P., Yu, H., MacNeil, D. J., Van der Ploeg, L. H., and Guan, X. M. (1998). Distribution of orexin receptor mRNA in the rat brain. FEBS Lett. 438, 71-75. doi: 10.1016/S0014-5793(98)01266-6

Tsuneki, H., Wada, T., and Sasaoka, T. (2010). Role of orexin in the regulation of glucose homeostasis. Acta Physiol. (Oxf.) 198, 335-348. doi: 10.1111/j.17481716.2009.02008.x

Van Baak, M. A. (2008). Meal-induced activation of the sympathetic nervous system and its cardiovascular and thermogenic effects in man. Physiol. Behav. 94, 178186. doi: 10.1016/j.physbeh.2007.12.020

Van Vliet-Ostaptchouk, J. V., Nuotio, M. L., Slagter, S. N., Doiron, D., Fischer, K., Foco, L., et al. (2014). The prevalence of metabolic syndrome and metabolically healthy obesity in Europe: a collaborative analysis of ten large cohort studies. BMC Endocr. Disord. 14:9. doi: 10.1186/1472-6823-14-9

Venner, A., Karnani, M. M., Gonzalez, J. A., Jensen, L. T., Fugger, L., and Burdakov, D. (2011). Orexin neurons as conditional glucosensors: paradoxical regulation of sugarsensing by intracellular fuels. J. Physiol. 589, 5701-5708. doi: 10.1113/jphysiol.2011.217000

Viggiano, A., Viggiano, A., Monda, M., Turco, I., Incarnato, L., Vinno, V., et al. (2006). Annurca apple-rich diet restores long-term potentiation and induces behavioral modifications in aged rats. Exp. Neurol. 199, 354-361. doi: 10.1016/j.expneurol.2006.01.001

Wang, Y., and Beydoun, M. A. (2007). The obesity epidemic in the United States - gender, age, socioeconomic, racial/ethnic, and geographic characteristics: a systematic review and meta-regression analysis. Epidemiol. Rev. 29, 6-28. doi: 10.1093/epirev/mxm007
Welle, S., Schwartz, R. G., and Statt, M. (1991). Reduced metabolic rate during $\beta$-adrenergic blockade in humans. Metabolism 40, 619-622. doi: 10.1016/00260495(91)90053-Y

Weyer, C., Snitker, S., Rising, R., Bogardus, C., and Ravussin, E. (1999). Determinants of energy expenditure and fuel utilization in man: effects of body composition, age, sex, ethnicity and glucose tolerance in 916 subjects. Int. J. Obes. Relat. Metab. Disord. 23, 715-722. doi: 10.1038/sj.ijo.0800910

Wolf, G. (1998). Orexins: a newly discovered family of hypothalamic regulators of food intake. Nutr. Rev. 56, 172-173. doi: 10.1111/j.1753-4887.1998.tb06131.x

Yach, D., Suckler, D., and Brownel, K. (2006). Epidemiologic and economic consequences of the global epidemics of obesity and diabetes. Nat. Med. 12, 62-66. doi: 10.1038/nm0106-62

Yi, C. X., Serlie, M. J., Ackermans, M. T., Foppen, E., Buijs, R. M., Sauerwein, H. P., et al. (2009). A major role for perifornical orexin neurons in the control of glucose metabolism in rats. Diabetes 58, 1998-2005. doi: 10.2337/db09-0385

Zhang, S., Blache, D., Vercoe, P. E., Adam, C. L., Blackberry, M. A., Findlay, P. A., et al. (2005). Expression of orexin receptors in the brain and peripheral tissues of the male sheep. Regul. Pept. 124, 81-87. doi: 10.1016/j.regpep.2004.07.010

Zheng, H., Patterson, L. M., and Berthoud, H. R. (2005). Orexin-A projections to the caudal medulla and orexin-induced c-Fos expression, food intake, and autonomic function. J. Comp. Neurol. 485, 127-142. doi: 10.1002/cne.20515

Conflict of Interest Statement: The authors declare that the research was conducted in the absence of any commercial or financial relationships that could be construed as a potential conflict of interest.

Received: 31 May 2014; accepted: 21 August 2014; published online: 08 September 2014.

Citation: Messina G, Dalia C, Tafuri D, Monda V, Palmieri F, Dato A, Russo A, De Blasio S, Messina A, De Luca V, Chieffi S and Monda M (2014) OrexinA controls sympathetic activity and eating behavior. Front. Psychol. 5:997. doi: 10.3389/fpsyg.2014.00997

This article was submitted to Eating Behavior, a section of the journal Frontiers in Psychology.

Copyright (C) 2014 Messina, Dalia, Tafuri, Monda, Palmieri, Dato, Russo, De Blasio, Messina, De Luca, Chieffi and Monda. This is an open-access article distributed under the terms of the Creative Commons Attribution License (CC BY). The use, distribution or reproduction in other forums is permitted, provided the original author(s) or licensor are credited and that the original publication in this journal is cited, in accordance with accepted academic practice. No use, distribution or reproduction is permitted which does not comply with these terms. 